\title{
Does body growth impair immune function in a large herbivore?
}

\author{
L. Cheynel ${ }^{1}$ (I) F. Douhard ${ }^{5} \cdot$ E. Gilot-Fromont ${ }^{1,2} \cdot$ B. Rey ${ }^{1} \cdot$ F. Débias ${ }^{1} \cdot$ S. Pardonnet ${ }^{1} \cdot$ J. Carbillet $^{3} \cdot$ H. Verheyden $^{3}$. \\ A. J. M. Hewison ${ }^{3} \cdot$ M. Pellerin ${ }^{4} \cdot$ J.-M. Gaillard ${ }^{1} \cdot$ J.-F. Lemaître ${ }^{1}$
}

\begin{abstract}
According to the principle of allocation, trade-offs are inevitable when resources allocated to one biological function are no longer available for other functions. Growth, and to a lesser extent, immunity are energetically costly functions that may compete with allocation to reproductive success and survival. However, whether high allocation to growth impairs immune system development during the growing period or immune system performance during adulthood is currently unknown in wild mammals. Using three roe deer (Capreolus capreolus) populations experiencing contrasting environmental conditions, we tested for potential costs of growth on immune phenotype over both the short-term (during growth), and the long-term (during adulthood) over the course of an individuals' life. We investigated potential costs on a set of 12 immune traits that reflect both innate and adaptive responses, and compared them between sexes and populations. Although fast growth tended to be associated with low levels of some humoral traits (globulins) during the growing period and some cellular immune traits (i.e. eosinophil and neutrophil counts) during adulthood, evidence for a trade-off between growth and other immune components was limited. Unexpectedly, no detectable growth costs on immunity were found in females from the population experiencing the least favourable environment. We discuss our findings in the light of the complex interplay between resource allocation strategies among reproduction, maintenance and immunity, in relation to local environmental conditions experienced by roe deer.
\end{abstract}

Keywords Body mass $\cdot$ Eco-immunology $\cdot$ Life history $\cdot$ Roe deer $\cdot$ Trade-off

\section{Introduction}

Growth is a key life history trait that shapes reproductive success and both short-term and long-term survival in most organisms. Developing a large body rapidly can buffer the effects of fluctuating environmental conditions (Dmitriew

L. Cheynel

louise.cheynel@univ-lyon1.fr

1 Université de Lyon, Université Lyon 1, UMR CNRS 5558, Villeurbanne Cedex, France

2 Université de Lyon, VetAgro Sup, Marcy-l'Etoile, France

3 CEFS, Université de Toulouse, INRA, Castanet Tolosan, France

4 Office National de la Chasse et de la Faune Sauvage, Centre National de Recherches Appliquées sur les Cervidés-Sanglier, Bar-le-Duc, France

5 GenPhySE, Université de Toulouse, INRA, INPT, INP-ENVT, 31320 Castanet Tolosan, France
2011) and allows juveniles to spend less time at the critical early-life stage, when they are particularly vulnerable to predators (Metcalfe and Monaghan 2003; Ronget et al. 2018). Large mature males are generally more successful in intra- and inter-sexual competition, and have thereby higher reproductive success than small males (Andersson 1994), while large females often exhibit higher fecundity than small ones (Roff 1992). A large body size can be attained either by an extended developmental period, an accelerated growth rate, or both (Metcalfe and Monaghan 2003). However, growth entails substantial energy and nutrient requirements (Wieser 1994), which are expected to have deleterious consequences on individual physiological performance and 
survival during prime-age adulthood and old age (Arendt and Wilson 1997; Blanckenhorn 2000; Dmitriew 2011).

Physiological and survival costs associated with rapid growth have been documented for several decades, notably in some of the first contributions to the evolutionary biology of aging (Williams 1957). Such relationships are embedded in the principle of allocation (Cody 1966), which states that individuals must allocate the limited amount of energy they acquire from their environment among the competing functions of growth, reproduction and survival. Most studies on vertebrate populations performed in the wild to date have focused on the energy allocation trade-off between current reproduction and subsequent survival or reproduction (Stearns 1992; Lemaître et al. 2015; Gélin et al. 2015). So far, the long-term effect of fast growth has been investigated much less. Yet, high energy allocation to body growth could be at the expense of energy allocated to the maintenance of cellular and physiological functions (McDade 2005). In the wild, restriction of food resources likely exacerbates energy allocation trade-offs. Harsh environmental conditions and low levels of food resources slow down growth (Arendt and Wilson 1997) and lead to delayed sexual maturity or reduced adult size, or both (Bonenfant et al. 2009). However, compensatory growth (sensu Hector and Nakagawa 2012) can occur, enabling juveniles to recover partially or fully from food limitation during early life. This compensatory growth is also associated with various and pronounced physiological costs, both over the short- and long-term throughout the course of an individual's life (Metcalfe and Monaghan 2001). Thus, although it is possible to recover a normal growth trajectory at some stage, slow growth during early life can have profound, pervasive and long-standing effects on individual adult performance (Metcalfe and Monaghan 2001). The costs of compensating for a bad start may include a faster rate of telomere attrition (Geiger et al. 2012), decreased physiological condition during adulthood (e.g. low tolerance to food restriction, Dupont-Prinet et al. 2010), an increased rate of senescence (e.g. more rapid loss of body mass in late adulthood, Douhard et al. 2017) or even a shortening of lifespan (Lee et al. 2013).

Immunity is a key physiological trait that potentially mediates life history trade-offs between growth and reproduction or between growth and survival (Sheldon and Verhulst 1996; Lochmiller and Deerenberg 2000; Zuk and Stoehr 2002; Lee 2006). Immune function determines an individual's sensitivity to infections and diseases, and thus affects both reproductive success and survival in the wild (Sheldon and Verhulst 1996; Schmid-Hempel 2003). The immune system is also a major physiological mechanism involved in cellular renewal and repair, and as such, is an essential component of somatic maintenance (McDade 2005). So far, the majority of studies that have focused on the trade-off between growth and immunity have been performed in birds (e.g. Soler et al. 2003, Brommer 2004; Mauck et al. 2005). Of these, experimental work based on food supplementation has shown that the immune response is resource dependent (Soler et al. 2003; Brommer 2004), a prerequisite for an energy allocation trade-off to occur. However, experiments based on parasite challenge or immune stimulation in young birds revealed that immune challenge affects the immune profile and body condition, but does not limit growth (Hõrak et al. 2000), and may even result in accelerated wing development (Saino et al. 1998; Szàp and Møller 1999). These previous studies, generally based on the manipulation of immunity in growing individuals, found limited impact on their growth, possibly because the amount of energy required for the immune response is much lower than that required for tissue growth (Klasing 1998). On the contrary, it is not known whether high allocation to growth could be costly over the short-term (i.e. for immune development) or over the long-term (i.e. for immune performance during adulthood). Specifically, rapid growth is more likely to compete with the most energy demanding traits such as cellular immunity than with less costly ones such as humoral functions (Klasing 2004). In addition, rapid growth may also carry a higher cost in terms of timing of immune development because individuals with low immune function in early life may accelerate their immune development later in life (Mauck et al. 2005; Rossi et al. 2013).

Here we tested for potential costs of early growth on immunity in young and adult roe deer, and of late growth on adult immunity. We collected data in both sexes on 12 immune traits encompassing both the innate and adaptive components of the immune response for 300 roe deer sampled during their growing period, and for 196 roe deer sampled during adulthood. These animals originated from three populations which have been intensively monitored using Capture-Mark-Recapture for over 20-30 years (Gaillard et al. 2013; Hewison et al. 2009). The populations are subjected to very different environmental conditions, which leads to marked differences in life history (notably growth rate, see Gaillard et al. 1997) and immunological (Cheynel et al. 2017) traits. Based on the principle of allocation and knowledge gained from empirical studies, we predicted that (i) a negative association should occur between early growth and immune traits over the short-term (i.e. during the growing period) in young roe deer, in particular for adaptive immunity that develops more progressively compared to innate immunity; (ii) a negative association should occur between early and/or late growth and adult immune traits over the long-term (i.e. during adulthood); (iii) immunity costs of late growth should be higher than those of early growth; (iv) the trade-off between growth and long-term immunity should be stronger for the most costly immune functions (in particular, cellular innate immunity, e.g. neutrophils, monocytes) than for less costly ones (typically, 
antibody response); (v) the trade-off should be strongest in the population experiencing the poorest environmental conditions. Finally, we also controlled for sex-specific effects because studies performed in laboratory and natural systems have reported that levels of immune performance are generally higher in females than in males (Zuk and McKean 1996). However, we expected the association between either early or late growth with immunity to be similar in males and females because roe deer only display a low intensity of sexual selection (Andersen et al. 1998), and because no clear sex differences were reported in physiological traits and intensity of parasitism in the studied populations (Cheynel et al. 2017).

\section{Materials and methods}

\section{Study populations and data collection}

We used data from three populations of roe deer: two are located in enclosed forests in north-eastern France $\left(48^{\circ} 43^{\prime} \mathrm{N}\right.$, $\left.4^{\circ} 55^{\prime} \mathrm{E}, 1360 \mathrm{ha}\right)$ at Trois-Fontaines, and in western France $\left(46^{\circ} 50^{\prime} \mathrm{N}, 0^{\circ} 25^{\prime} \mathrm{W}, 2614 \mathrm{ha}\right)$ at Chizé; and the third population is located at Aurignac, in a rural site in the southwest of France $\left(43^{\circ} 17^{\prime} \mathrm{N}, 0^{\circ} 53^{\prime} \mathrm{E}, 7500 \mathrm{ha}\right)$.

The Trois-Fontaines population is exposed to a continental climate characterized by cold winters and warm rainy summers. This site has rich soils and provides high habitat quality for roe deer. In contrast, the Chizé population has a temperate oceanic climate with Mediterranean influences, and frequent summer droughts combined with poor soils, resulting in limited forest productivity (Pettorelli et al. 2006). Hence, fawn survival, female fertility, adult body mass (Gaillard et al. 2013), age-specific telomere length (Wilbourn et al. 2017); and many markers of immune performance (Cheynel et al. 2017) are consistently lower at Chizé than at Trois-Fontaines. Aurignac has an oceanic climate with summer droughts and is a mixed landscape of woodland patches, meadows and crops offering high quality resources for roe deer (Abbas et al. 2011).
As part of the long-term Capture-Mark-Recapture program initiated in the late 1970 s for the two forest populations and in 2001 for the Aurignac population, 6-12 days of capture occur between December and March each year (see Gaillard et al. 1993; Morellet et al. 2009 for details about the capture sessions). In May-June, newborn fawns are also captured annually. Roe deer caught within their first year of birth (i.e. either as newborn or as 8-month-old individuals during winter captures) are identified using tooth eruption patterns (Hewison et al. 1999). At capture, we recorded body mass (to the nearest $50 \mathrm{~g}$ ) and performed a basic clinical examination. We collected blood samples from the jugular vein (up to $20 \mathrm{~mL}$ for a $20 \mathrm{~kg}$ roe deer). We performed cell counts within $52 \mathrm{~h}$ of sampling on whole blood preserved on EDTA at $4{ }^{\circ} \mathrm{C}$. We also extracted and conserved serum at $-20{ }^{\circ} \mathrm{C}$ for measures of functional activities (see below).

The two forest populations of roe deer (Trois-Fontaines and Chizé) were used for the analyses of both short-term and long-term costs of rapid growth on immune performance. The population of Aurignac was included for the analysis investigating the short-term consequences of rapid growth on immune performance only since the exact age of most adults is unknown at this site (Hewison et al. 2009).

\section{Dataset}

We used data from known-aged individuals that were bloodsampled at least once during their lifetime between 2010 and 2016. Roe deer usually gain most of their adult body mass (more than 90\%) within the first 2 years of life, but only reach their full adult mass at about 4 years of age (Hewison et al. 2011). When not faced with strong food limitation, females start to give birth at 2 years of age (Gaillard et al. 1992), while most males father their first offspring during their fourth year of life (Vanpé et al. 2009). Adult immune performance was measured as the median of each immune trait during adulthood (i.e. between 4 and 9 years of age). Based on these age-classes, data on immunity were collected for a total of 300 growing animals (i.e. sampled at 8 months of age) in the three populations (see details in Table 1). At Aurignac, we only used data for growing roe

Table 1 Sex- and population-specific sample sizes

\begin{tabular}{|c|c|c|c|c|c|c|c|}
\hline \multirow[t]{2}{*}{ Subset } & \multicolumn{2}{|l|}{ Chizé } & \multicolumn{2}{|c|}{ Trois-Fontaines } & \multicolumn{2}{|l|}{ Aurignac } & \multirow[t]{2}{*}{ Total } \\
\hline & Females & Males & Females & Males & Females & Males & \\
\hline $\begin{array}{l}\text { Immunity measures at } 8 \text { months of age (individuals with } \\
\text { measure of early growth) }\end{array}$ & $\begin{array}{l}59 \\
(59)\end{array}$ & $\begin{array}{l}71 \\
(71)\end{array}$ & $\begin{array}{l}68 \\
(68)\end{array}$ & $\begin{array}{l}61 \\
(61)\end{array}$ & $\begin{array}{l}20 \\
(20)\end{array}$ & $\begin{array}{l}21 \\
(21)\end{array}$ & $\begin{array}{l}300 \\
(300)\end{array}$ \\
\hline $\begin{array}{l}\text { Immunity measures during adulthood [4-9 years of age] (indi- } \\
\text { viduals with early and late growth measures) }\end{array}$ & $\begin{array}{l}61 \\
(43)\end{array}$ & $\begin{array}{l}39 \\
(28)\end{array}$ & $\begin{array}{l}51 \\
(33)\end{array}$ & $\begin{array}{l}45 \\
(20)\end{array}$ & - & - & $\begin{array}{l}196 \\
(124)\end{array}$ \\
\hline $\begin{array}{l}\text { Immunity measures during growth and adulthood (individuals } \\
\text { with growth measures) }\end{array}$ & $\begin{array}{l}6 \\
(3)\end{array}$ & $\begin{array}{l}10 \\
(2)\end{array}$ & $\begin{array}{l}11 \\
(11)\end{array}$ & $\begin{array}{l}5 \\
(5)\end{array}$ & - & - & $\begin{array}{l}32 \\
(21)\end{array}$ \\
\hline
\end{tabular}


deer (i.e. at 8 months of age, $n=41$ ) since the sample size for known-aged adults was too small to perform a detailed analysis $(n=9)$. Data on immunity were also collected for a total of 196 prime-aged adults (i.e. sampled between 4 and 9 years of age) at Chizé and Trois-Fontaines. Data were approximately equally distributed between sexes (Table 1). These immune measures on roe deer at Trois-Fontaines and Chizé have already been the subject of a previous analysis on immunosenescence patterns (see Cheynel et al. 2017).

Owing to the relatively recent start of immunity assessments in the monitoring programs (2010) and to the imperfect detection rate during the capture-recapture season (i.e. recapture rate of about 0.5; Gaillard et al. 1993), only 32 out of the 196 adults with immunity measures also had immunity measures during their growing period (Table 1). Growth measures (i.e. early and late growth, see below for a definition of these metrics) were based on records of both body mass at first capture (at about 8 months of age) and on adult body mass (between 4 and 6 years of age, before body mass senescence starts; Douhard et al. 2017).

\section{Immunity measures}

We measured a set of 12 immune traits to depict both the innate and adaptive responses, represented by both humoral and cell-mediated components (Roitt et al. 1998). We assessed the cellular part of immunity by measuring the total white blood cell (WBC) count and assessing the composition of the white blood cell population (five different cell types, measured in $10^{3}$ cells $/ \mathrm{mL}$ ), based on the identification of the first hundred WBC in Wright-Giemsa-stained blood smears (Houwen 2001; Gilot-Fromont et al. 2012). Neutrophils and monocytes are phagocytic cells of the innate response. Basophils and eosinophils participate in the inflammatory response and play a role in the innate response against parasites, but eosinophils are also involved in the adaptive response. Finally, lymphocytes include $\mathrm{T}$ and $\mathrm{B}$ cells, B cells being specifically involved in the production of antibodies. Innate humoral immunity was assessed by measuring both the circulating levels of natural antibodies (NAbs) and the complement-mediated cell lysis activity. We used the hemagglutination-hemolysis (HAHL) assay (Matson et al. 2005, see also Gilot-Fromont et al. 2012 for a previous study on roe deer). In this assay, the HA score (measured in titre) measures the ability of NAbs to agglutinate exogenous cells and provides a proxy of the NAbs concentration, and HL score measures the ability of these NAbs to cause hemolysis. Innate humoral immunity also includes numerous proteins involved in acute and chronic inflammatory processes. We thus measured the levels of alpha1-globulin, alpha2-globulin and beta-globulin, which include several acute phase proteins of the inflammatory response. Total protein content (in $\mathrm{g} / \mathrm{L}$ ) was first assessed by refractometry, followed by automatic agarose gel electrophoresis (HYDRASYS, Sebia, Evry, France) that separates albumin and the 4 fractions of globulins (alpha1, alpha2, beta, and gamma). We also measured the specific level of haptoglobin (HAP in $\mathrm{mg} / \mathrm{mL}$ ), a protein that belongs to the alpha2-globulin fraction which is synthesized in cases of chronic infection or inflammation. Haptoglobin analyses were performed on a Konelab 30i automaton (Fisher Thermo Scientific, Cergy-Pontoise, France) using phase Haptoglobin assay (Tridelta Development LTD, County Kildare, Ireland) chromogenic kit. Contrary to the other immune parameters, haptoglobin was only measured at Chizé and Trois-Fontaines. The humoral component of the adaptive immunity response was assessed by measuring the concentration of gamma-globulins (see above for details about the electrophoresis protocol), i.e., immunoglobulins, which represent the majority of circulating antibodies. Detailed protocols for measuring each of the immune parameter are provided in Online Resource 1. For adult animals with repeated measures of immune traits between 4 and 9 years of age ( 82 individuals sampled twice or more), we estimated within-individual repeatability of our immune measures and their $95 \%$ confidence interval (CI) using the R package rptR (Nakagawa and Schielzeth 2010). We found that the majority of adult immune traits were consistent over time (repeatability of between 0.22 and 0.41 for the various forms of white blood cells, between 0.03 and 0.46 for various forms of globulins and between 0.07 and 0.42 for HAHL, results provided in Online Resource 1).

\section{Growth measures}

Early growth (i.e. adjusted body mass at 8 months of age, which was labelled as "early mass" in Douhard et al. 2017) and late growth (i.e. a compound of early growth and growth from 8 months of age to adulthood) were defined and calculated as in Douhard et al. (2017). Most births take place around mid-May ( $80 \%$ within less than 25 days, Gaillard et al. 1993), while annual winter captures occur from midDecember to early March. We could not measure postnatal growth rate per se (i.e. growth between birth and 8 months) because the exact birth date was unknown for those fawns that were first marked during the winter captures.

We indexed early growth as fawn mass at winter capture (i.e. about 8 months of age) adjusted to the median date of capture (i.e. January $27 \mathrm{th}$ ). This adjustment is required because fawns in the studied populations continue to grow during their first winter (Hewison et al. 2002), although their mass at capture is mostly the accumulated product of growth from birth to early October, when weaning takes place (Andersen et al. 1998). From the body mass data, the average daily mass gain throughout the winter capture period was $12 \pm 0.005(\mathrm{SE}) \mathrm{g} \mathrm{day}^{-1}$ at Chizé, $24 \pm 0.008 \mathrm{~g} \mathrm{day}^{-1}$ at Trois-Fontaines (Douhard et al. 2017), and 30 $\pm 0.005 \mathrm{~g}$. 
day $^{-1}$ at Aurignac (linear regression with date of capture as the sole covariate; no sex-difference was detected). As individual variation in early growth was partly due to variation in environmental conditions during the year of birth (Gaillard et al. 1996), we further adjusted early growth relative to the average fawn mass of each cohort in each population.

Late growth corresponded to the post-weaning growth from about 8 months to 4 years of age. When calculating late growth we accounted for variation in mass at 8 months of age because fawns that grow slowly early in life subsequently tend to grow faster than fawns that grow fast early in life. This late growth was thus measured for each sex and each population as the residuals of the linear regression between early growth and subsequent mass gain, which corresponds to the difference between adult body mass (i.e. the median body mass between 4 and 6 years of age) and early growth. As such, early growth and late growth were statistically independent.

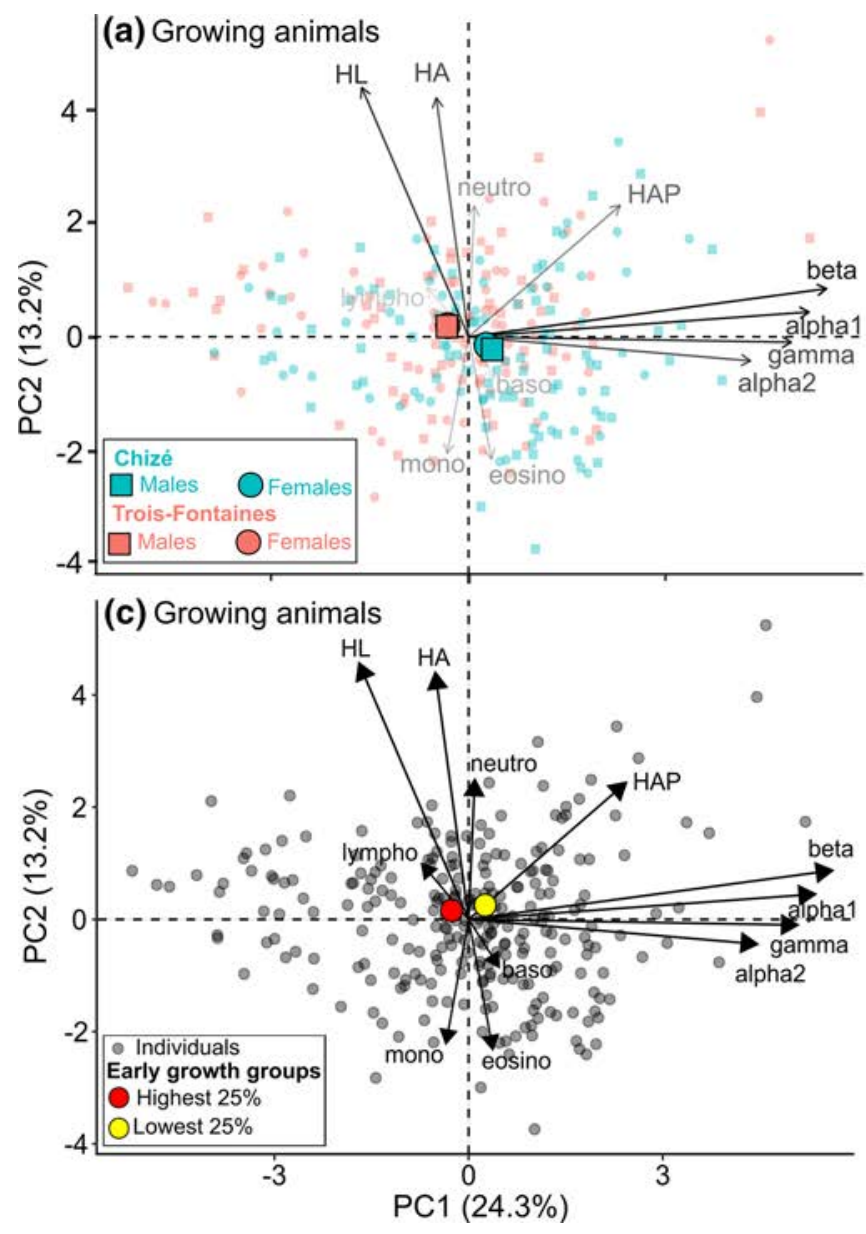

Fig. 1 Biplots of PCA analyses of the 12 immunity traits measured during $\mathbf{a}, \mathbf{c}$ the growing period, and $\mathbf{b}, \mathbf{d}$ adulthood in $\mathbf{a}, \mathbf{b}$ female and male roe deer of the two populations (Chizé and Trois-Fontaines), and in c, $\mathbf{d}$ individuals with extremely fast (top 25\%) or slow (bottom $25 \%$ ) growth. Arrows indicate the contribution of immune traits

\section{Assessing covariation among immunity traits}

We performed a principal component analysis (PCA) on the 12 immune traits to identify the main axes of variation that determined their correlation structure. We thus examined whether the immune traits could be clustered into a few biologically meaningful and independent components (corresponding to PCs). We examined covariation among the 12 immune traits in both growing and adult animals to assess the consistency of the immune phenotype over the lifetime at Chizé and Trois-Fontaines, and to identify potential differences in relation to sex and population (see Fig. 1 and Table 2). We did not include Aurignac in the PCA analysis because haptoglobin concentration was not assayed in this population. In the analyses, we removed individuals that contributed abnormally to the PCs, possibly because of a severe inflammatory state (i.e. 2 and 1
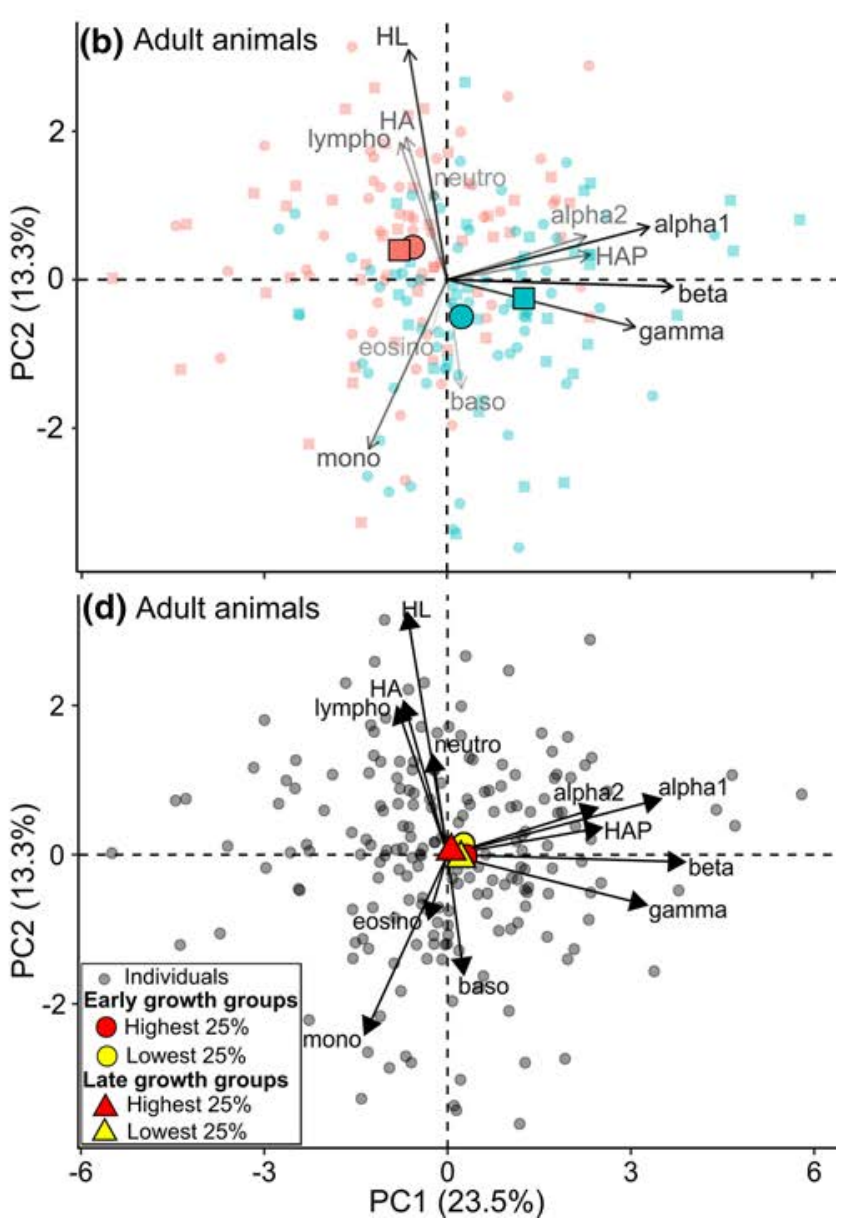

to each of the first two PCs (i.e. longer and darker arrows denote stronger correlations). Small symbols indicate individual coordinates on the first two PCs. Average PCs scores are reported by the larger symbols. See text for definition of variables 
Table 2 Average sex-specific immune measures observed in the three roe deer populations, at Aurignac, Chizé and Trois-Fontaines

\begin{tabular}{|c|c|c|c|c|c|c|c|c|c|}
\hline \multirow[t]{2}{*}{ Immune trait } & \multicolumn{2}{|l|}{ Chizé } & \multicolumn{2}{|c|}{ Trois-Fontaines } & \multicolumn{2}{|l|}{ Aurignac } & \multicolumn{3}{|l|}{ Effects } \\
\hline & Females & Males & Females & Males & Females & Males & Population & Sex & Interaction \\
\hline \multicolumn{10}{|l|}{ Growing animals } \\
\hline Globulin levels (PC1) & $0.27^{\mathrm{a}}$ & $0.36^{\mathrm{a}}$ & $-0.32^{\mathrm{a}}$ & $-0.33^{\mathrm{a}}$ & - & - & $* *$ & - & - \\
\hline Cellular immunity (PC2) & $-0.15^{\mathrm{a}}$ & $-0.22^{\mathrm{a}}$ & $0.20^{\mathrm{a}}$ & $0.18^{\mathrm{a}}$ & - & - & $*$ & - & - \\
\hline Alpha1-globulin & $3.59^{\mathrm{a}}$ & $3.60^{\mathrm{a}}$ & $3.57^{\mathrm{a}}$ & $3.58^{\mathrm{a}}$ & $3.48^{\mathrm{a}}$ & $3.37^{\mathrm{a}}$ & - & - & - \\
\hline Alpha2-globulin & $5.55^{\mathrm{ab}}$ & $6.09^{\mathrm{ac}}$ & $5.91^{\mathrm{a}}$ & $5.56^{\mathrm{ab}}$ & $4.47^{\mathrm{bc}}$ & $4.30^{\mathrm{b}}$ & $* * *$ & - & - \\
\hline Haptoglobin & $0.13^{\mathrm{a}}$ & $0.14^{\mathrm{a}}$ & $0.15^{\mathrm{a}}$ & $0.16^{\mathrm{a}}$ & - & - & - & - & - \\
\hline Beta-globulin & $5.99^{\mathrm{a}}$ & $5.89^{\mathrm{a}}$ & $5.59^{\mathrm{a}}$ & $5.52^{\mathrm{a}}$ & $5.14^{\mathrm{a}}$ & $5.30^{\mathrm{a}}$ & $* * *$ & - & - \\
\hline Gamma-globulin & $18.24^{\mathrm{a}}$ & $17.88^{\mathrm{a}}$ & $13.31^{\mathrm{b}}$ & $14.11^{\mathrm{b}}$ & $10.08^{c}$ & $9.69^{c}$ & $* * *$ & - & - \\
\hline Neutrophil count & $4.34^{\mathrm{ac}}$ & $4.06^{\mathrm{a}}$ & $5.80^{\mathrm{d}}$ & $5.67^{\mathrm{d}}$ & $5.53^{\text {bcd }}$ & $5.89^{\text {bd }}$ & $* * *$ & - & - \\
\hline Monocyte count & $0.42^{\text {ade }}$ & $0.45^{\mathrm{ad}}$ & $0.33^{\mathrm{cd}}$ & $0.26^{\mathrm{ce}}$ & $0.08^{\mathrm{bc}}$ & $0.17^{\text {bce }}$ & $* * *$ & - & - \\
\hline Basophil count & $0.06^{\mathrm{a}}$ & $0.09^{\mathrm{a}}$ & $0.05^{\mathrm{a}}$ & $0.05^{\mathrm{a}}$ & $0.06^{\mathrm{a}}$ & $0.07^{\mathrm{a}}$ & - & - & - \\
\hline Lymphocyte count & $2.38^{\mathrm{abd}}$ & $2.03^{\mathrm{a}}$ & $2.69^{\text {bef }}$ & $2.37^{\mathrm{abd}}$ & $3.00^{\mathrm{cdf}}$ & $2.72^{\text {ace }}$ & $* * *$ & $*$ & - \\
\hline Eosinophil count & $0.06^{\mathrm{a}}$ & $0.07^{\mathrm{a}}$ & $0.05^{\mathrm{a}}$ & $0.07^{\mathrm{a}}$ & $0.05^{\mathrm{a}}$ & $0.04^{\mathrm{a}}$ & - & - & - \\
\hline HA & $4.59^{\mathrm{a}}$ & $4.59^{\mathrm{a}}$ & $4.10^{\mathrm{a}}$ & $4.08^{\mathrm{a}}$ & $3.70^{\mathrm{a}}$ & $3.83^{\mathrm{a}}$ & $* * *$ & - & - \\
\hline HL & $1.78^{\mathrm{a}}$ & $1.98^{\mathrm{a}}$ & $2.02^{\mathrm{a}}$ & $2.30^{\mathrm{a}}$ & $3.05^{\mathrm{b}}$ & $3.33^{\mathrm{b}}$ & $* * *$ & - & - \\
\hline \multicolumn{10}{|l|}{ Adult animals } \\
\hline Globulins (PC1) & $0.237^{\mathrm{b}}$ & $1.263^{\mathrm{a}}$ & $-0.56^{\mathrm{c}}$ & $-0.78^{\mathrm{c}}$ & - & - & $* * *$ & - & $* *$ \\
\hline Cellular immunity (PC2) & $0.50^{\mathrm{a}}$ & $0.25^{\mathrm{a}}$ & $-0.43^{\mathrm{b}}$ & $-0.40^{\mathrm{b}}$ & - & - & $* * *$ & - & - \\
\hline Alpha1-globulin & $3.03^{\mathrm{a}}$ & $3.35^{\mathrm{b}}$ & $3.16^{\mathrm{ab}}$ & $3.12^{\mathrm{ab}}$ & - & - & - & - & $*$ \\
\hline Alpha2-globulin & $5.83^{\mathrm{a}}$ & $5.76^{\mathrm{a}}$ & $5.70^{\mathrm{a}}$ & $5.35^{\mathrm{a}}$ & - & - & - & - & - \\
\hline Haptoglobin & $0.21^{\mathrm{ab}}$ & $0.78^{\mathrm{a}}$ & $0.14^{\mathrm{b}}$ & $0.17^{\mathrm{c}}$ & - & - & $* *$ & $* * *$ & $* *$ \\
\hline Beta-globulin & $7.19^{\mathrm{ab}}$ & $8.36^{\mathrm{a}}$ & $6.61^{\mathrm{b}}$ & $6.44^{\mathrm{c}}$ & - & - & $* * *$ & $*$ & $* *$ \\
\hline Gamma-globulin & $20.28^{\mathrm{a}}$ & $20.89^{\mathrm{a}}$ & $15.20^{\mathrm{b}}$ & $14.53^{b}$ & - & - & $* * *$ & - & - \\
\hline Neutrophils & $5.18^{\mathrm{b}}$ & $5.05^{\mathrm{b}}$ & $6.42^{\mathrm{a}}$ & $6.01^{\mathrm{ab}}$ & - & - & $* * *$ & - & - \\
\hline Monocytes & $0.31^{\mathrm{a}}$ & $0.31^{\mathrm{a}}$ & $0.32^{\mathrm{a}}$ & $0.35^{\mathrm{a}}$ & - & - & - & - & - \\
\hline Basophils & $0.08^{\mathrm{a}}$ & $0.08^{\mathrm{a}}$ & $0.05^{\mathrm{a}}$ & $0.07^{\mathrm{a}}$ & - & - & - & - & - \\
\hline Lymphocyte count & $1.62^{\mathrm{b}}$ & $1.62^{\mathrm{b}}$ & $2.33^{\mathrm{a}}$ & $2.12^{\mathrm{a}}$ & - & - & $* * *$ & - & - \\
\hline Eosinophil count & $0.11^{\mathrm{a}}$ & $0.09^{\mathrm{a}}$ & $0.11^{\mathrm{a}}$ & $0.06^{\mathrm{a}}$ & - & - & - & $*$ & - \\
\hline HA & $3.96^{\mathrm{a}}$ & $3.90^{\mathrm{a}}$ & $4.04^{\mathrm{a}}$ & $4.20^{\mathrm{a}}$ & - & - & - & - & - \\
\hline HL & $1.84^{\mathrm{b}}$ & $2.07^{\mathrm{ab}}$ & $2.25^{\mathrm{ab}}$ & $2.47^{\mathrm{a}}$ & - & - & $*$ & - & - \\
\hline
\end{tabular}

Level of statistical significance denoted by asterisk: $* p<0.05, * *<0.01, * * *<0.001$. Means within rows sharing a common character in their superscript are not statistically different $(p>0.05)$ based on pairwise comparisons (Tukey's test)

individuals that contributed to $28.7 \%$ and $17 \%$ of the first axis among growing and adult animals, respectively).

Finally, to assess whether 'slow' and 'fast' growing roe deer displayed an overall difference in immune traits, we calculated the average PC coordinates of the fastest growers (top 25\%,n=66 for growing and $n=37$ for adult animals) and of the slowest growers (bottom $25 \%, \mathrm{n}=66$ for growing and $n=37$ for adult animals) after separating them within sex and population (see Fig. 1). To test whether the slowest growers differed in overall immune function from the fastest growers, we used a non-parametric PerMANOVA test ('adonis2' function in the $\mathrm{R}$ package vegan; Oksanen et al. 2013).

The PCA was performed using the R package 'ade4' (Dray and Dufour 2007). Differences in average trait measures between sexes and populations were assessed using a two-way ANOVA followed by Tukey's post hoc test using the multcomp R-package (Hothorn et al. 2008) (Table 2).

\section{Assessing the short-term and long-term growth costs on immunity}

We investigated, in both growing and adult animals, the effects of growth on the two first axes of covariation in immunity traits (i.e. first and second PCs, which roughly correspond to continuums of the level of globulins (PC1) and of the cellular part of immunity (PC2); see Fig. 1). Growth effects corresponded to early growth in growing animals, and to both early growth and late growth in adults. Firstly, 
we assessed the magnitude and the precision of these effects from their 'effect size' and CI (Nakagawa and Cuthill 2007). Secondly, to assess whether variation in individual growth explained variation in immune function, we performed a model selection procedure using an information-theoretic approach (Burnham and Anderson 2002).

Within each sex and population, we calculated 'effect size' as the partial correlation coefficients, which measure the standardized effect of one growth measure on an immune trait while controlling for the potential effects of other traits. To obtain the effect sizes, for each immune trait we first fitted the mixed-effect model including early growth, late growth (only in adults), and average cohort fawn mass as fixed factors and cohort as a random effect on the intercept (i.e. additive model). We then used Eq. (24) in Nakagawa and Cuthill (2007, p. 82) for mixed-effect models to calculate effect size. We calculated CI of effect sizes following Nakagawa and Cuthill (2007)'s recommendations (i.e. using the 'es calculator', see http://cebcp.org/practical-meta-analy sis-effect-size for further information). We also calculated the effect size of growth on each of the 12 immune traits separately (see Online Resource 2 for growing and adult roe deer). As data for growing roe deer at Aurignac could not be included in the PCA analysis (see above), we assessed effect size of early growth on individual immune traits separately in this population (results presented in Online Resource 2).

Using the information-theoretic approach, we fitted several candidate linear mixed-effect models of immunity traits, which either included or did not include early and late growth as covariates (supplementary methods in Online Resource 3, and best models selected in Online Resource 4 for growing animals and adults). We investigated a possible population- or sex-specific effect of growth on the immune phenotype by fitting models including either three-way interaction (i.e. growth (early or late) $\times$ population $\times$ sex) or twoway interactions involving growth (see Online Resource 3 for the full list of models). Models were ranked based on the Akaike Information Criterion corrected for small sample size (AICc, Burnham and Anderson 2002) in the R package MuMIn (Bartoń, 2016). We selected the model with the lowest AICc. When the difference in AIC (denoted $\triangle \mathrm{AICc}$ ) of two competing models was less than 2 , we retained the model with the lowest number of parameters in accordance with parsimony rules. In addition, we calculated AIC weights $(\omega \mathrm{i})$ to measure the relative likelihood that a given model was the best among the set of fitted models. All linear mixed-effect models were fitted using restricted maximum likelihood ('Imer' function in the R package lme4; Bates et al., 2015) to estimate model parameters. As data for growing roe deer at Aurignac could not be included in the PCA analysis (see above), we selected models separately for each immune trait in this population (Online Resource 4). All analyses were carried out in $\mathrm{R}$ version 3.4.1 ( $\mathrm{R}$ Core Team 2015).

\section{Results}

\section{Covariation among immune traits during growth and adulthood}

The main axis of covariation among immune traits (PC1) accounted for $24.3 \%$ and $23.5 \%$ of the total inertia for growing and adult roe deer, respectively (Fig. 1). In both cases, PC1 was mostly influenced by the five globulin concentrations: gamma- $(r=0.81$ and 0.75 in growing and adult roe deer, respectively), beta- ( $r=0.90$ and 0.90$)$, alpha1$(r=0.85$ and 0.80$)$, alpha2-globulin $(r=0.71$ and 0.55$)$, and haptoglobin $(r=0.38$ and 0.57$)$. PC1 could thus be directly interpreted as a continuum of the humoral part of innate immunity. In the following analyses, we used PC1 as a continuum for globulin levels.

PC2 captured around $13.2 \%$ and $13.3 \%$ of the total inertia in growing and adult roe deer, respectively (Fig. 1). It mostly reflected variation in cellular immunity. In both growing and adult roe deer, $\mathrm{PC} 2$ was positively correlated with markers of natural antibodies (HL: $r=0.72$ and 0.75 ; HA: $r=0.69$ and $0.46)$, neutrophil count $(r=0.38$ and 0.29$)$ and lymphocyte count $(r=0.14$ and $r=0.45)$. PC2 was negatively correlated with monocyte $(r=-0.34$ and -0.55$)$, eosinophil $(r=-0.29$ and $r=-0.18)$ and basophil $(r=-0.12$ and -0.35$)$ counts. Our analyses revealed clear consistency between the immune phenotype of growing and adult individuals.

The similarity in the structure of correlations between immune traits (Fig. 1) most likely resulted from high and consistent between-population differences in the level of immune traits at both life stages (Table 2). As expected, both growing animals and adults had higher globulin levels at Chizé than at Trois-Fontaines. In contrast, both growing animals and adults had higher neutrophil and lymphocyte counts at Trois-Fontaines than at Chizé (Table 2). In growing animals, no sex-difference was detected for most immune traits except for lymphocytes, which were higher in females than in males. In adult animals, we detected sex differences for eosinophils, which were higher in females than in males in adults of both populations; and for haptoglobin, which were higher in males than in females (Table 2). Finally, the growth type (i.e. slow or fast) did not influence the immune profile of either young or adult roe deer (Fig. 1). Thus, there were no differences between slowest (i.e. bottom $25 \%$ ) and fastest (i.e. top 25\%) growing roe deer in either early growth in growing $(F=1.37, d f=12,132, p=0.21)$ and adult $(F=0.80, d f=12,74, p=0.56)$ roe deer, or in late growth in adult roe deer $(F=0.40, d f=12,132, p=0.79)$. 


\section{Short-term effects of early growth on immunity traits in growing roe deer}

\section{Effect size}

In growing roe deer with known values of early growth $(n=300$, see Table 1), effect sizes for early growth in relation to immunity traits were mostly negligible (Fig. 2). At Trois-Fontaines and Chizé, no relationship was found between early growth and globulin level (PC1, Fig. 2),

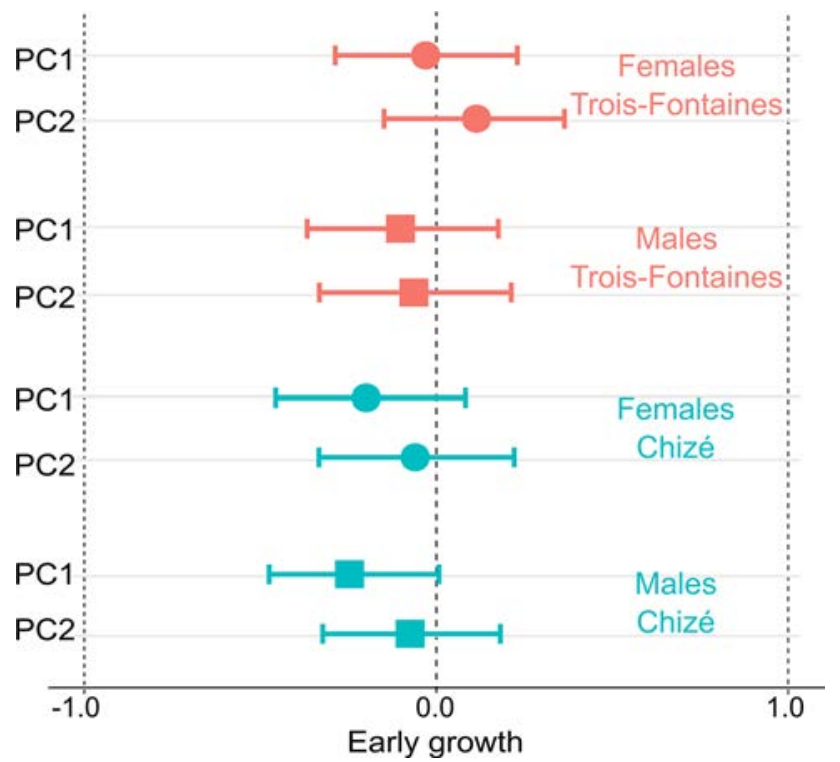

Fig. 2 Effect size of early growth on the two main axes of covariation among immune traits (PC1, PC2) measured in growing roe deer (at 8 months of age) at Chizé and Trois-Fontaines. Effect sizes (symbols) are reported together with associated $95 \%$ confidence interval cellular immunity (PC2, Fig. 2) or immune traits separately (Online Resource 2). At Aurignac, we found a negative effect of early growth on neutrophil count in males (effect size: $-0.48[-0.76 ;-0.06])$. The magnitude of this effect was, however, not consistent with that observed at Chizé or Trois-Fontaines.

\section{Selected models}

Based on this approach, we only found support for an overall negative relationship between early growth and PC1 across both sexes and all populations (model selection in Online Resource 3 and selected models detailed in Online Resource 4). More specifically, the selected model for the two main immune traits contributing to PC1 included a negative effect of early growth, that is for alpha1-globulins at Chizé (Fig. 3a, slope of $-0.11 \pm 0.04, p<0.01$ ) and gamma-globulins in all three populations (Fig. 3b, slope of $-0.36 \pm 0.09$, $p<0.001)$.

\section{Long-term effects of early and late growth on immunity traits in adult roe deer}

\section{Effect size}

Based on effect sizes for early and late growth in adult roe deer from both Trois-Fontaines and Chizé (124 out of 196 roe deer available to characterize immunity during adulthood, Table 1), evidence for substantial long-term growth costs on immunity was overall weak and heterogeneous (Fig. 4 and Online Resource 2). In both Trois-Fontaines and Chizé, although several immune traits taken separately were negatively associated with early or late growth (Online Resource 2), no significant association was observed
Fig. 3 Negative effect of early growth on two traits of humoral immunity of fawns (8 months old) in a Chizé, and $\mathbf{b}$ in the three populations of Aurignac and Trois-Fontaines
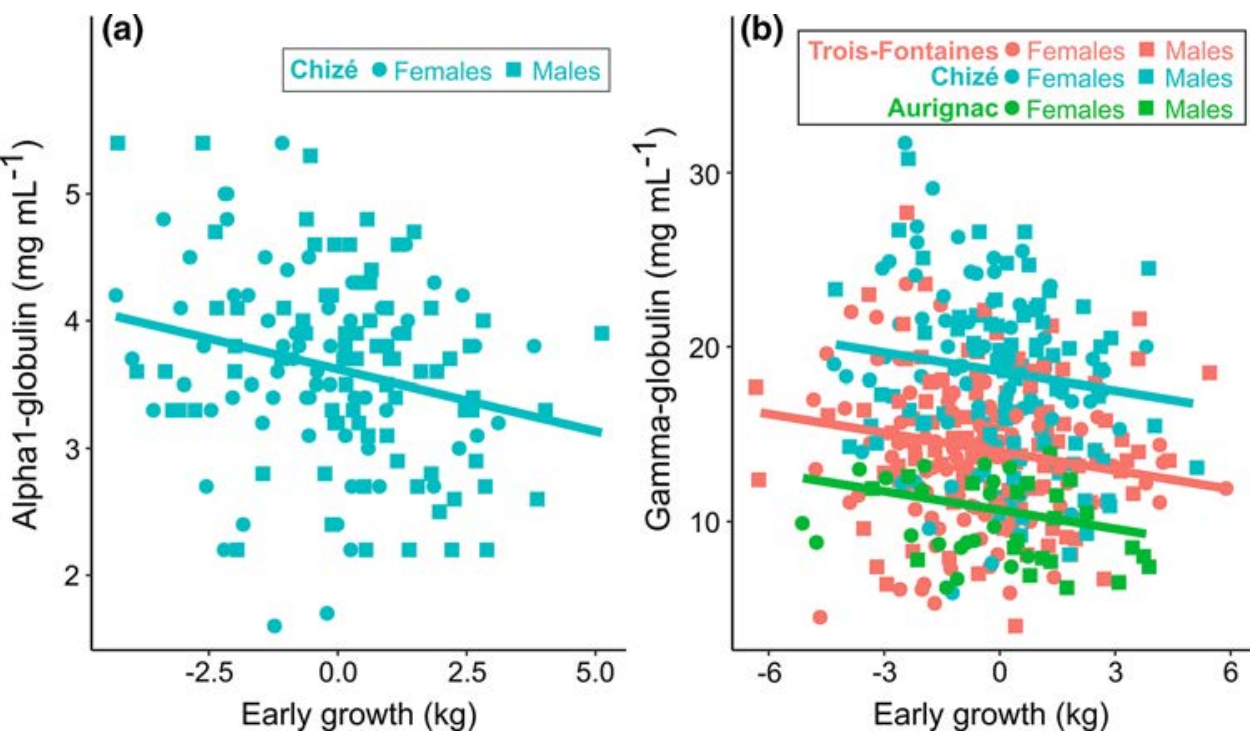


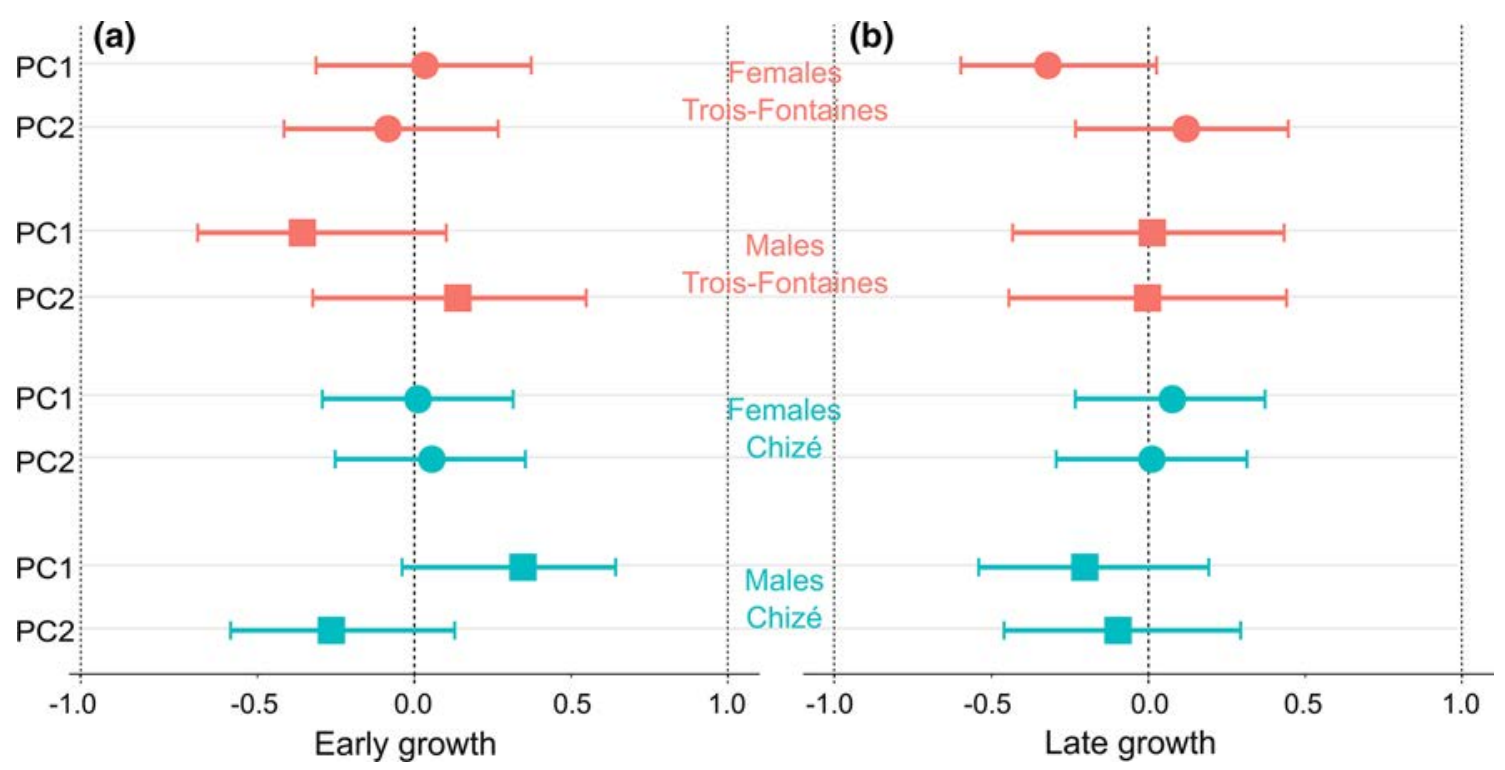

Fig. 4 Effect size of $\mathbf{a}$ early growth and $\mathbf{b}$ late growth on the two main axes of covariation among immune traits (PC1/PC2) measured in adult roe deer (from 4 to 9 years of age included) at Chizé

and Trois-Fontaines. Effect sizes (symbols) are reported together with associated $95 \%$ confidence interval

between early or late growth and either globulin level (PC1) or cellular immunity (PC2).

\section{Selected models}

The model selection procedure did not support any effect of our growth metrics on immune function, except for two immune traits that strongly contributed to PC2 (model selection in Online Resource 3 and selected models detailed in Online Resource 4): the eosinophil count

in males (model selected: [early growth $\times$ sex], Online Resource 4) and the neutrophil count (model selected: [early growth $\times$ pop + late growth], Online Resource 4). More precisely, the eosinophil count was negatively affected by early growth in males in the two populations (Fig. 5a), slope of $-0.03 \pm 0.01, p<0.01$ ). Finally, the neutrophil count was negatively affected by early growth at Trois-Fontaines only (Fig. 5b), slope of $-0.24 \pm 0.11$, $p<0.05$ ) and by late growth in both populations (Fig. 5c), slope of $-0.22 \pm 0.09, p<0.05)$.
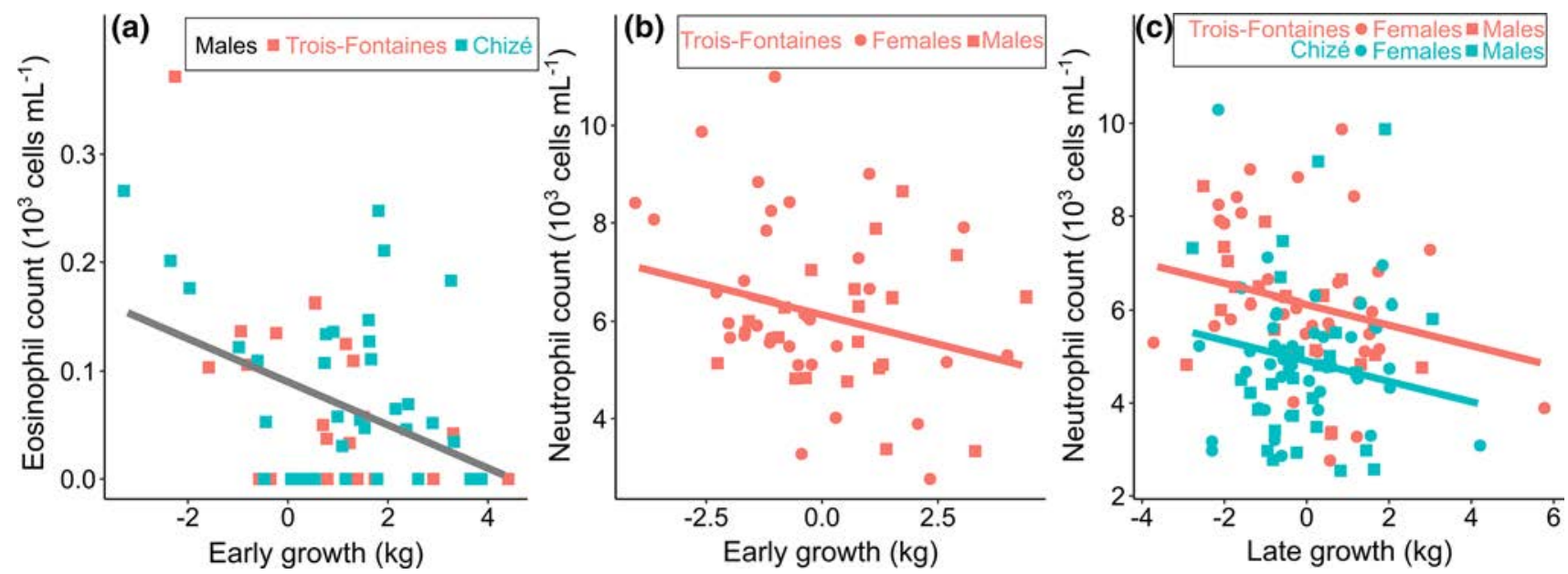

Fig. 5 Negative effect of early or late growth on two traits of cellular immunity of adult roe deer (from 4 to 9 years of age included) in a males of the two populations of Chizé and Trois-Fontaines, $\mathbf{b}$ both sexes in Trois-Fontaines, and $\mathbf{c}$ both sexes and both populations 


\section{Discussion}

We tested for potential short-term and long-term costs of growth on immunity in a large herbivore in three freeranging populations facing markedly different ecological conditions. Overall, we found only limited evidence for the expected costs of growth on roe deer immunity, both over the short-term during immune development (at 8 months), and over the longer-term during adulthood (between 4 and 9 years of age). In growing animals, we found that a high rate of early growth led to a decrease in the levels of some globulins (gamma-globulins in all populations and alpha1-globulins at Chizé). Similarly, in adults, the level of some immune traits was slightly negatively impacted by a high rate of both early and late growth. In the adult males of two populations, both neutrophil and eosinophil counts were lower in individuals which had grown fast. In female adults of two populations, a high rate of late growth negatively impacted the neutrophil count, while a similar relationship with early growth was observed in females from Trois-Fontaines only. Long-term growth costs thus generally tended to affect the cellular part of the immune response, mostly the number of neutrophils and eosinophils. The fact that the various components of the immune system were differentially affected by growth is consistent with our hypothesis that immune functions are not equally costly to produce and maintain. As reported by previous studies (Klasing 2004), our results support the assertion that innate and cellular components of immunity are more costly to produce over the long-term than adaptive and humoral immune components. Consequently, although some cellular immune traits might be impaired by fast growth, the evidence for growth costs on other immune components is far from evident in roe deer. Our results also highlight that, contrary to our expectations, high late growth that potentially includes compensatory growth does not lead to higher costs for the immune response than early growth. Finally, although Trois-Fontaines provides clearly more suitable habitat for roe deer than Chizé (based on higher wood production, plant productivity and homogeneity of the forest, see details in Pettorelli et al. 2006), roe deer at Chizé did not seem to pay higher growth costs on immunity than those at Trois-Fontaines.

Obviously, our study had some limitations that might partly account for the overall findings of an absence of a marked trade-off between growth and immunity in roe deer. The two main axes of our PCA only accounted for $30 \%$ of the total variation in the immune measures, indicating that a substantial proportion of variation remains. Low resolution in our immune measures might account for this low explanatory power of the PCA, because measuring immunity in wild species is challenging. Indeed, access to wild animals is difficult, and standardized measurement techniques have still to be developed for non-model species such as roe deer. The immune measures in our study provide a general pattern of energy allocation to the two components of the immune response, which is consistent over the long-term, as indicated by the substantial withinindividual repeatability we found in adults. Although our measures were taken without considering the previous history of pathogen exposure, these baseline levels have been shown to be related to the response to previous challenges (Schneeberger et al. 2014), and to be strongly associated with survival in some mammals in the wild (Rossi et al. 2013 on wild boar Sus scrofa, Garnier et al. 2017 on Soay sheep Ovis aries). However, short-term variation in some immune parameters in response to specific immune challenges may obscure the observed pattern, in particular, for parameters displaying short-term responses such as haptoglobin or alpha-globulins. Some of these measures could also be improved to assess immune allocation more precisely, for example, by discriminating different populations of lymphocytes, and/or by conducting functional immunological tests. Lastly, our assessment of growth could potentially be improved and a more detailed assessment of the growth curve might have enabled a better detection of trade-offs. Since we did not have repeated measures of body mass in our populations, we used mass gain between 8 months of age and adulthood as a proxy of growth. Although this prevented us from deriving a very detailed growth trajectory, it still provided relevant information on individual allocation to growth for our model species. Indeed, roe deer display a monomolecular pattern of growth, involving a peak in growth rate at birth which then consistently decreases with increasing age (Portier et al. 2000).

Besides the methodological limitations reviewed above, a possible explanation for the absence of a clear trade-off between growth and immunity in the present study might be due to the lack of information on reproductive effort. While the patterns of covariation between growth and immune performance that have been reported so far are highly variable (see e.g. Saino et al. 1998, Hõrak et al. 2000, Mauck et al. 2005), most studies (including ours) ignored the fact that available resources have to be partitioned among growth, reproduction, and a broad range of physiological functions related to survival (Stearns 1992; Kirkwood and Rose 1991). High allocation to reproduction during early life is generally associated with long-term fitness (Lemaître et al. 2015, but see Panagakis et al. 2017) and physiological costs (e.g. Bauch et al. 2013; Hanssen et al. 2005) in wild vertebrates. Although most studies have been performed in females, recent evidence suggests that the same might be true in males (Lemaître et al. 2014; Beirne et al. 2015). Therefore, a decline in immune performance might, in some species, 
be only apparent in individuals that allocate substantially to both growth and reproduction (e.g. gestation and lactation in females or energy allocation to traits associated with sexual competition in males). Studies on laboratory or farm animals that have been intensely selected for high productivity (growth or reproduction) have shown that, despite ad libitum access to nutrient-dense food, a downregulation of immune function can occur when immunity is not purposely selected for (Van der Most et al. 2011). The trade-offs involving reproduction might be particularly pronounced in roe deer females that rely almost exclusively on available food resources during breeding and do not store body reserves to meet the energetic requirements of reproduction (i.e. income breeder reproductive tactic, Andersen et al. 2000). Cumulative costs of growth and reproduction might even be more pronounced in harsh environments such as Chizé, where roe deer females show higher between-year variation in reproductive success, than in Trois-Fontaines or Aurignac (Gaillard et al. 2013). Females of long-lived iteroparous species faced with harsh conditions are selected to favour their own survival over their offspring survival (Gaillard and Yoccoz 2003), which could explain the absence of costs paid on immunity by females at Chizé and their lower allocation to reproduction when faced with food shortage (Gaillard et al. 1992). The trade-off between growth and immune development may also be stronger in degraded habitats because habitat quality and biodiversity both contribute to shape pathogen burden and parasite selective pressure (Civitello et al. 2015; Young et al. 2013).

Optimal strategies relative to the maintenance or the regulation of the immune system also depend a lot on the pathogen pressure of the environment, and the optimal allocation of resources among different components of immunity is context-specific. Parasites and pathogens generate a threat to survival and infections are one of the causes potentially jeopardizing juvenile survival (Sams et al. 1996; Lynsdale et al. 2017). The 'antigen-exposure' hypothesis points to ecological variation in pathogen pressure as being a key determinant of observed variation in immunity (McDade et al. 2016). This hypothesis predicts that, in environments with high pathogenic pressure, overall allocation to immune function will be greater, and/or that adaptive immunity will be prioritized over innate immunity if the costs of increasing allocation to all components of the immune function are exceedingly large. At Chizé, young roe deer faced high parasite pressure, for instance of Trichuris sp. (Cheynel et al. 2017). It is therefore crucial for them to allocate energy to immunity during body development. This strong allocation to immunity from the early stages until adulthood could explain the overall absence of a trade-off between growth and immunity, especially at Chizé. At Trois-Fontaines, roe deer are less exposed to parasites and have more resources available to mount an efficient immune response. Additionally, the high parasite pressure on young roe deer at Chizé could result in the selective disappearance of lower quality individuals and especially young roe deer unable to allocate to both immunity and growth, a selection expected to be weaker at Trois-Fontaines. Finally, if nutritional resources are limited, as is expected to be the case at Chizé, immune components that require fewer resources, both in the shortterm but also in the long-term, should be favoured. Even if allocating preferentially to adaptive immunity requires the payment of upfront costs, especially when food is limited, adaptive immunity should be favoured in the long run in anticipation of deferred future benefits and given the lower maintenance and per-response activation costs, compared to the innate responses (McDade et al. 2016). In line with previous studies (Gilot-Fromont et al. 2012; Cheynel et al. 2017), these findings support the assertion that roe deer allocate more to adaptive immunity from the youngest age at Chizé than at Trois-Fontaines.

In this study, we showed that young roe deer pay only negligible costs of growing rapidly in terms of immune performance. However, it is likely that high allocation to growth, especially late in the growing period (after weaning), can affect physiological functions other than immunity, which might have deleterious consequences on fitness components later in life. For instance, roe deer that grow fast late in the growing period suffered from a steeper rate of mass senescence than slower growers (Douhard et al. 2017). These findings illustrate the complexity of detecting physiological costs and trade-offs in the wild, especially when immune responses are involved (Sandland and Minchella 2003).

Acknowledgements We thank all the ONCFS staff, in particular Claude Warnant and Gilles Capron, the local hunting associations, the Fédération Départementale des Chasseurs de la Haute Garonne and the field volunteers for the organisation of the roe deer captures. We thank Corinne Régis, Marie-Thérèse Poirel, Slimania Benabed, Damien Jouet and Elodie Moissonier for their help in the laboratory analyses and Anne-Béatrice Dufour for statistical advices. We also warmly thank two anonymous referees whose insightful comments substantially improved the manuscript. This work was supported by grants from the Agence Nationale de la Recherche (ANR-15-CE32-0002-01) and the ONCFS (Grants 2011/18/6171 and 2015/19/6171), and performed within the framework of the LABEX ECOFECT (ANR-11-LABX-0048) of Université de Lyon, within the program "Investissementsd'Avenir" (ANR11-IDEX-0007) operated by the French National Research Agency (ANR).

Author contribution statement JFL, JMG, EGF conceived the study and designed methodology; all authors collected the data; LC, EGF, BR, HV performed the immunological measures; LC and FD analysed the data; $\mathrm{LC}$ wrote the first draft of the paper and all authors contributed critically to the drafts and gave approval for the final version. 


\section{Compliance with ethical standards}

Conflict of interest The authors declare that they have no conflict of interest.

Ethical approval All applicable institutional and/or national guidelines for the care and use of animals were followed. For Trois-Fontaines and Chizé populations, the protocol of capture and blood sampling of roe deer under the authority of the Office National de la Chasse et de la Faune Sauvage (ONCFS) was approved by the Director of Food, Agriculture and Forest (Prefectoral order 2009-14 from Paris). All procedures were approved by the Ethical Committee of Lyon 1 University (project DR2014-09, June 5, 2014). For the Aurignac population, the study was permitted by the land manager of both sites, the Office National des Forêts (ONF) and prefecture of Haute Garonne (Partnership Convention ONCFS-ONF dated 2005-12-23). All procedures were approved by the Ethical Committee 115 of Toulouse (project APAFIS\#7880-2016120209523619v5).

\section{References}

Abbas F, Morellet N, Hewison AJM, Merlet J, Cargnelutti B, Lourtet B, Angibault JM, Daufresne T, Aulagnier S, Verheyden H (2011) Landscape fragmentation generates spatial variation of diet composition and quality in a generalist herbivore. Oecologia 167:401-411

Andersen R, Duncan P, Linnell JDC (1998) The European roe deer: the biology of success. Scandinavian University Press, Oslo

Andersen R, Gaillard JM, Linnell JDC, Duncan P (2000) Factors affecting maternal care in an income breeder, the European roe deer. $\mathrm{J}$ Anim Ecol 69:672-682

Andersson MB (1994) Sexual Selection. Princeton University Press, Princeton

Arendt JD, Wilson DS (1997) Optimistic growth: competition and an ontogenetic niche-shift select for rapid growth in pumpkinseed sunfish (Lepomis gibbosus). Evolution 51:1946-1954

Bartoń K (2016) MuMIn: multi-model inference. R package version 1.15.6. https://cran.r-project.org/web/packages/MuMIn/index.html

Bates D, Maechler M, Bolker B, Walker S (2015) Fitting linear mixedeffects models using lme4. J Stat Softw 67:1

Bauch C, Becker PH, Verhulst S (2013) Telomere length reflects phenotypic quality and costs of reproduction in a long-lived seabird. Proc R Soc B 280:20122540

Beirne C, Delahay R, Young A (2015) Sex differences in senescence: the role of intra-sexual competition in early adulthood. Proc $\mathrm{R}$ Soc B 282:20151086

Blanckenhorn WU (2000) The evolution of body size: what keeps organisms small? Q Rev Biol 75:385-407

Bonenfant C, Gaillard JM, Coulson T, Festa-Bianchet M, Loison A, Garel M, Egil Loe L, Blanchard P, Pettorelli N, Owen-Smith N, Du Toit J, Duncan P (2009) Empirical evidence of density dependence in populations of large herbivores. Adv Ecol Res 41:314-345

Brommer JE (2004) Immunocompetence and its costs during development: an experimental study in blue tit nestlings. Proc R Soc B 7:S110-S113

Burnham KP, Anderson DR (2002) Model selection and multimodel inference: a practical information-theoretic approach. Springer, New York

Cheynel L, Lemaitre JF, Gaillard JM, Rey B, Bourgoin G, Ferté H, Jégo M, Débias F, Pellerin M, Jacob L, Gilot-Fromont E (2017) Immunosenescence patterns differ between populations but not between sexes in a long-lived wild mammal. Sci Rep 7:13700
Civitello DJ, Cohen J, Fatima H, Halstead NT, Liriano J, McMahon TA, Ortega CN, Sauer EL, Sehgal T, Young S, Rohr JR (2015) Biodiversity inhibits parasites: broad evidence for the dilution effect. Proc Nat Acad Sci 112:8667-8671

Cody ML (1966) A general theory of clutch size. Evolution 20:174-184

Dmitriew CM (2011) The evolution of growth trajectories: what limits growth rate? Biol Rev 86:97-116

Douhard F, Gaillard JM, Pellerin M, Jacob L, Lemaître JF (2017) The cost of growing large: costs of post-weaning growth on body mass senescence in a wild mammal. Oikos 126:1329-1338

Dray S, Dufour AB (2007) The ade4 package: implementing the duality diagram for ecologists. J Stat Softw 22:1-20

Dupont-Prinet A, Chatain B, Grima L, Vandeputte M, Claireaux G, McKenzie DJ (2010) Physiological mechanisms underlying a trade-off between growth rate and tolerance of feed deprivation in the European sea bass (Dicentrarchus labrax). J Exp Biol 213:1143-1152

Gaillard JM, Yoccoz NG (2003) Temporal variation in survival of mammals: a case of environmental canalization? Ecology 84:3294-3306

Gaillard JM, Sempéré AJ, Boutin JM, Van Laere C, Boisaubert B (1992) Effects of age and body weight on the proportion of females breeding in a population of roe deer (Capreolus capreolus). Can J Zool 70:1541-1545

Gaillard JM, Delorme D, Boutin JM, Van Laere G, Boisaubert B, Pradel R (1993) Roe deer survival patterns - a comparative analysis of contrasting populations. J Anim Ecol 62:778-791

Gaillard JM, Delorme D, Boutin JM, Van Laere G, Boisaubert B (1996) Body mass of roe deer fawns during winter in 2 contrasting populations. J Wild Manag 60:29-36

Gaillard JM, Boutin JM, Delorme D, Van Laere G, Duncan P, Lebreton JD (1997) Early survival in roe deer: causes and consequences of cohort variation in two contrasted populations. Oecologia 112:502-513

Gaillard JM, Hewison AJ, Klein F, Plard F, Douhard M, Davison R, Bonenfant C (2013) How does climate change influence demographic processes of widespread species? Lessons from the comparative analysis of contrasted populations of roe deer. Ecol Lett 16:48-57

Garnier R, Cheung CK, Watt KA, Pilkington JG, Pemberton JM, Graham AL (2017) Joint associations of blood plasma proteins with overwinter survival of a large mammal. Ecol Lett 20:175-183

Geiger S, Le Vaillant M, Lebard T, Reichert S, Stier A, Le Maho Y, Criscuolo F (2012) Catching-up but telomere loss: half-opening the black box of growth and ageing trade-off in wild king penguin chicks. Mol Ecol 21:1500-1510

Gélin U, Wilson ME, Cripps J, Coulson G, Festa-Bianchet M (2015) Individual heterogeneity and offspring sex affect the growthreproduction trade-off in a mammal with indeterminate growth. Oecologia 180:1127-1135

Gilot-Fromont E, Jégo M, Bonenfant C, Gibert P, Rannou B, Klein F, Gaillard JM (2012) Immune phenotype and body condition in roe deer: individuals with high body condition have different, not stronger immunity. PLoS One 7:e45576

Hanssen SA, Hasselquist D, Folstad I, Erikstad KE (2005) Cost of reproduction in a long-lived bird: incubation effort reduces immune function and future reproduction. Proc R Soc B 272:1039-1046

Hector KL, Nakagawa S (2012) Quantitative analysis of compensatory and catch-up growth in diverse taxa. J Anim Ecol 81:583-593

Hewison AJM, Vincent JP, Angibault JM, Delorme D, Van Laere G, Gaillard JM (1999) Tests of estimation of age from tooth wear on roe deer of known age: variation within and among populations. Can J Zool 77:58-67 
Hewison AJM, Gaillard JM, Blanchard P, Festa-Bianchet M (2002) Maternal age is not a predominant determinant of progeny sex ratio variation in ungulates. Oikos 98:334-339

Hewison AJM, Morellet N, Verheyden H, Daufresne T, Angibault JM, Cargnelutti B, Merlet J, Picot D, Rames JL, Joachim J, Lourtet B, Serrano E, Bideau E (2009) Landscape fragmentation influences winter body mass of roe deer. Ecography 32:1062-1070

Hewison AJM, Gaillard JM, Delorme D, Van Laere G, Amblard T, Klein F (2011) Reproductive constraints, not environmental conditions, shape the ontogeny of sex-specific mass-size allometry in roe deer. Oikos 120:1217-1226

Hõrak P, Ots I, Tegelmann L, Møller AP (2000) Health impact of phytohaemagglutinin-induced immune challenge on great tit (Parus major) nestlings. Can J Zool 78:905-910

Hothorn T, Bretz F, Westfall P (2008) Simultaneous inference in general parametric models. Biom J 50:346-363

Houwen B (2001) The differential cell count. Lab Hematol 7:89-100

Kirkwood TBL, Rose MR (1991) Evolution of senescence - late survival sacrificed for reproduction. Philos Trans R Soc B 332:15-24

Klasing KC (1998) Nutritional modulation of resistance to infectious diseases. Poultry Sci 77:1119-1125

Klasing KC (2004) The costs of immunity. Acta Zool Sin 50:961-969

Lee KA (2006) Linking immune defenses and life history at the levels of the individual and the species. Int Comput Biol 46:1000-1015

Lee WS, Monaghan P, Metcalfe NB (2013) Experimental demonstration of the growth rate-lifespan trade-off. Proc R Soc B 280:20122370

Lemaître JF, Gaillard JM, Pemberton JM, Clutton-Brock TH, Nussey DH (2014) Early life expenditure in sexual competition is associated with increased reproductive senescence in male red deer. Proc R Soc B 281:20140792

Lemaître JF, Berger V, Bonenfant C, Douhard M, Gamelon M, Plard F, Gaillard JM (2015) Early-late life trade-offs and the evolution of ageing in the wild. Proc R Soc B 282:20150209

Lochmiller RL, Deerenberg C (2000) Trade-offs in evolutionary immunology: just what is the cost of immunity? Oikos 88:87-98

Lynsdale CL, Mumby HS, Hayward AD, Mar KU, Lummaa V (2017) Parasite-associated mortality in a long-lived mammal: variation with host age, sex, and reproduction. Ecol Evol 7:1-12

Matson KD, Robert E, Ricklefs RE, Klasing KC (2005) A hemolysis-hemagglutination assay for characterizing constitutive innate humoral immunity in wild and domestic birds. Dev Comput Immunol 29:275-286

Mauck RA, Matson KD, Philipsborn J, Ricklefs RE (2005) Increase in the constitutive innate humoral immune system in Leach's Storm-Petrel (Oceanodroma leucorhoa) chicks is negatively correlated with growth rate. Funct Ecol 19:1001-1007

McDade TW (2005) Life history, maintenance, and the early origins of immune function. Am J Hum Biol 17:81-94

McDade TW, Georgiev AV, Kuzawa CW (2016) Trade-offs between acquired and innate immune defenses in humans. Evol Med Public Health 1:1-16

Metcalfe NB, Monaghan P (2001) Compensation for a bad start: grow now, pay later? Trends Ecol Evol 16:254-260

Metcalfe NB, Monaghan P (2003) Growth versus lifespan: perspectives from evolutionary ecology. Exp Gerontol 38:935-940

Morellet N, Verheyden H, Angibault JM, Cargnelutti B, Lourtet B, Hewison AJM (2009) The effect of capture on ranging behaviour and activity of the European roe deer Capreolus capreolus. Wildl Biol 15:278-287

Nakagawa S, Cuthill IC (2007) Effect size, confidence interval and statistical significance: a practical guide for biologists. Biol Rev Camb Philos Soc 82:591-605
Nakagawa S, Schielzeth H (2010) Repeatability for Gaussian and non-Gaussian data: a practical guide for biologists. Biol Rev 85:935-956

Oksanen J, Blanchet FG, Kindt R, Legendre P, Minchin PR, O'hara RB, Simpson GL, Solymos P, Stevens MHH, Szoecs E, Wagner H (2013) Package 'vegan'. Community ecology package, version, vol 2(9)

Panagakis A, Hamel S, Côté SD (2017) Influence of early reproductive success on longevity and late reproductive success in an alpine ungulate. Am Nat 189:667-683

Pettorelli N, Gaillard JM, Mysterud A, Duncan P, Stenseth NC, Delorme D, Van Laere G, Tö̈go C, Klein F (2006) Using a proxy of plant productivity (NDVI) to find key periods for animal performance: the case of roe deer. Oikos 112:565-572

Portier C, Duncan P, Gaillard JM, Guillon N, Sempéré AJ (2000) Growth of European roe deer: patterns and rates. Acta Theriol 45:87-94

R Core Team (2015) R: a language and environment for statistical computing. R Foundation for Statistical Computing, Vienna

Roff DA (1992) The evolution of life histories. Theory and analysis. Chapman and Hall, New York

Roitt I, Brostoff J, Male D (1998) Immunology. Mosby, Maryland

Ronget V, Gaillard JM, Coulson T, Garratt M, Gueyffier F, Lega JC, Lemaître JF (2018) Causes and consequences of variation in offspring body mass: meta-analyses in birds and mammals. Biol Rev. https://doi.org/10.1111/brv.12329

Rossi S, Doucelin A, Le Potier M-F, Eraud C, Gilot-Fromont E (2013) Innate immunity correlates with host fitness in wild boar (Sus scrofa) exposed to classical swine fever. PLoS One 8:e79706

Saino N, Calza S, Møller AO (1998) Effects of a dipteran ectoparasite on immune response and growth trade-offs in barn swallow, Hirundo rustica, nestlings. Oikos 81:217-228

Sams MG, Lochmiller RL, Qualls C, Leslie DM, Payton ME (1996) Physiological correlates of neonatal mortality in an overpopulated herd of white-tailed deer. J Mammal 77:179-190

Sandland G, Minchella DJ (2003) Costs of immune defense: an enigma wrapped in an environmental cloak? Trends Parasitol 19:571-574

Schmid-Hempel P (2003) Variation in immune defence as a question of evolutionary ecology. Proc. R. Soc. B 270:357-366

Schneeberger K, Courtiol A, Czirják GÁ, Voigt CC (2014) Immune profile predicts survival and reflects senescence in a small, longlived mammal, the greater sac-winged bat (Saccopteryx bilineata). PLoS One 9:e108268

Sheldon BC, Verhulst S (1996) Ecological immunology: costly parasite defences and trade-offs in evolutionary ecology. Trends Ecol Evol 11:317-321

Soler JJ, de Neve L, Pérez-Contreras T, Soler M, Sorci G (2003) Trade-off between immunocompetence and growth in magpies: an experimental study. Proc R Soc B 270:241-248

Stearns SC (1992) The evolution of life histories. Oxford University Press, Oxford

Szàp T, Møller AP (1999) Cost of parasitism and host immune defence in the sand martin Riparia riparia: a role for parentoffspring conflict? Oecologia 119:9-15

Van der Most PJ, de Jong B, Parmentier HK, Verhulst S (2011) Trade-off between growth and immune function: a meta-analysis of selection experiments. Funct Ecol 25:74-80

Vanpé C, Gaillard JM, Morellet N, Kjellander P, Liberg O, Delorme D, Hewison AJM (2009) Age-specific variation in male breeding success of a territorial ungulate species, the European roe deer. J Mammal 90:661-665

Wieser W (1994) Cost of growth in cells and organisms: general rules and comparative aspects. Biol Rev Camb Philos Soc 69:1-33 
Wilbourn RV, Froy H, McManus MC, Cheynel L, Gaillard JM, Gilot-Fromont E, Regis C, Rey B, Pellerin M, Lemaître JF, Nussey DH (2017) Age-dependent associations between telomere length and environmental conditions in roe deer. Biol Lett 13:20170434

Williams GC (1957) Pleiotropy, natural selection and the evolution of senescence. Evolution 11:398-411
Young H, Griffin RH, Wood CL, Nunn CL (2013) Does habitat disturbance increase infectious disease risk for primates? Ecol Lett 16:656-663

Zuk M, McKean KA (1996) Sex differences in parasite infections: patterns and processes. Int J Parasitol 26:1009-1023

Zuk M, Stoehr AM (2002) Immune defense and host life history. Am Nat 160:S9-S22 